Silvia Kurlat Ares, Introducción. La ciencia ficción en América Latina. Aproximaciones teóricas al imaginario de la experimentación cultural ... ..

\title{
I. MARCos TEÓRICOS: OTRAS HERRAMIENTAS
}

EZEQUIEL DE Rosso, Una compulsiva fidelidad: sobre tres historias nacionales

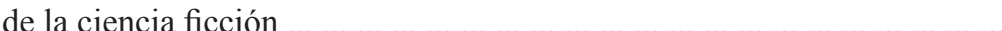

Carlos Abraham, Las literaturas de lo insólito. Una tipología ... ... ... ... ...

EdUARDO LEDESMA, Ciencia-ficción digital iberoamericana (mutantes, ciborgs y entes virtuales): La Red y la literatura electrónica del siglo

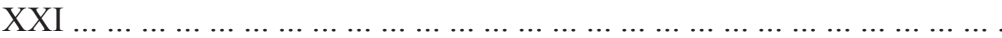

Hernán Manuel García, Hacia una poética de la tecnología periférica: Postcyberpunk y picaresca 2.0 en Sleep Dealer de Alex Rivera ... .............. .

Nelson Darío GonZÁlez, El neuropunk y la ciencia ficción hispanoamericana

TERESA LóPEZ-PellisA, El síndrome del misticismo agudo en la ciencia ficción peruana: La verdad sobre Dios y JBA: Novela esotérica y Un ejército de locos. Novela lunática de José B. Adolph ................................

Luis C. CAno, Apoteosis de la influencia, o de cómo los senderos de la ciencia ficción hispanoamericana conducen a Borges ....................

Silvia G. Kurlat Ares, Entre la utopía y la distopía: política e ideología en el discurso crítico de la ciencia ficción

Luis PESTARINI, Las ucronías en la literatura argentina

\section{ENTRE LAS LITERATURAS NACIONALES Y LA REFORMULACIÓN DE UN CORPUS CONTINENTAL}

JoAnna Page, Reflexividad en la obra de Eduardo Holmberg: el rol de la ciencia ficción y la fantasía en la modernización y el control de las masas

Mariano García, Bioy y sus precursores. La tradición de la ciencia ficción en la narrativa de Adolfo Bioy Casares 
ANOUCK LiNCK, Los caminos no conformes de la razón. Acercamiento teórico a la ciencia ficción y la literatura fantástica a partir de dos textos de Adolfo Bioy Casares y algunos conceptos matemáticos ......................

Héctor Fernández L'Hoeste, El futuro en cuentos: de ovnis e implantes oculares en la ciencia ficción mexicana

Giovanna Rivero, Señales que precederán al fin del mundo de Yuri Herrera: Una propuesta para un novum ontológico latinoamericano

Emily A. Maguire, Deformaciones literarias: Embriología, genealogía, y ciencia ficción en El Informe Cabrera de José "Pepe" Liboy ... ... ... ........

Pedro P. Porbén, Pus-modernidad e irreverencia en bandeja: Yoss y la ciencia ficción en Cuba en el Siglo XXI

ÉVERLy PEgoraro, A experiência urbana steampunk: entre a literatura de ficção científica e as ruas do Brasil ... ................................... .

JuAn Manuel Espinosa, Vuelos sobre lo nuevo. Ciencia ficción en Colombia 1928-1936

\section{OTRAS VOCES: MUJERES, HISTORIETA Y CINE}

Elton Honores, Después del fin: la historieta de ciencia ficción en el Perú ...

Henri-Simon Blanc-HoÀng, Planetas mestizos: un análisis de tres comics de ciencia ficción del Cono Sur

Miguel GARCíA, ¿Imaginar el futuro? 2033 y el resurgimiento del cine mexicano de ciencia ficción .

M. Elizabeth Ginway, Simios, ciborgues y reptiles: la oviparidad en obras de escritoras latinoamericanas de ciencia ficción y fantasía ..............

Nicole L. Sparling, La ciencia de género según Angélica Gorodischer ... .... .

\section{RESEÑAS}

Julieta Viu Adagio sobre Marcela Aguilar, Claudia Darrigrandi, Mariela Méndez y Antonia Viu, eds., Escrituras a ras de suelo. Crónica latinoamericana del siglo XX.

Arne Romanowski sobre April J. Mayes, The Mulatto Republic: Class, Race,

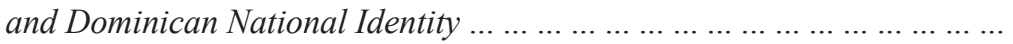

ERICK Ramos sobre José Ignacio Padilla, El terreno en disputa es el lenguaje. Ensayos sobre poesía latinoamericana .................................

Rafael Acosta Morales sobre Mariano Siskind, Cosmopolitan Desires: Global Modernity and World Literature in Latin America .................. 